Natural Hazards and Earth System Sciences (2004) 4: 711-717

SRef-ID: 1684-9981/nhess/2004-4-711

European Geosciences Union

(C) 2004 Author(s). This work is licensed

under a Creative Commons License.

\title{
Influence of weathering and pre-existing large scale fractures on gravitational slope failure: insights from 3-D physical modelling
}

\author{
D. Bachmann, S. Bouissou, and A. Chemenda \\ Géosciences Azur, UMR 6526, Université de Nice Sophia-Antipolis, 250 rue Albert Einstein, Sophia-Antipolis, 06560 \\ Valbonne, France
}

Received: 25 August 2004 - Revised: 9 November 2004 - Accepted: 10 November 2004 - Published: 17 November 2004

Part of Special Issue "Landslides and debris flows: analysis, monitoring, modeling and hazard"

\begin{abstract}
Using a new 3-D physical modelling technique we investigated the initiation and evolution of large scale landslides in presence of pre-existing large scale fractures and taking into account the slope material weakening due to the alteration/weathering. The modelling technique is based on the specially developed properly scaled analogue materials, as well as on the original vertical accelerator device enabling increases in the "gravity acceleration" up to a factor 50. The weathering primarily affects the uppermost layers through the water circulation. We simulated the effect of this process by making models of two parts. The shallower one represents the zone subject to homogeneous weathering and is made of low strength material of compressive strength $\sigma_{l}$. The deeper (core) part of the model is stronger and simulates intact rocks. Deformation of such a model subjected to the gravity force occurred only in its upper (low strength) layer. In another set of experiments, low strength $\left(\sigma_{w}\right)$ narrow planar zones sub-parallel to the slope surface $\left(\sigma_{w}<\sigma_{l}\right)$ were introduced into the model's superficial low strength layer to simulate localized highly weathered zones. In this configuration landslides were initiated much easier (at lower "gravity force"), were shallower and had smaller horizontal size largely defined by the weak zone size. Pre-existing fractures were introduced into the model by cutting it along a given plan. They have proved to be of small influence on the slope stability, except when they were associated to highly weathered zones. In this latter case the fractures laterally limited the slides. Deep seated rockslides initiation is thus directly defined by the mechanical structure of the hillslope's uppermost levels and especially by the presence of the weak zones due to the weathering. The large scale fractures play a more passive role and can only influence the shape and the volume of the sliding units.
\end{abstract}

Correspondence to: D. Bachmann

(bachmann@geoazur.unice.fr)

\section{Introduction}

Mountains are intrinsically heterogeneous due to both inherited geological structures and the effect of relatively shortterm processes such as weathering, alteration, and fracturing (Chigira, 1985; Gillon and Hancox; 1992, Agliardi et al., 2001). These factors cause the rock mass strength to decrease, in some cases up to gravitationally-induced slope failure. Strength reduction occurs mainly around the fractures as weathering is enhanced by fluid circulation. The fracture network may arise from tectonic loading, slope unloading after glacial retreat (Augustinus, 1995), and mineral inflation during the weathering itself (Wyns et al., 1999; Maréchal et al., 2003). Fracturing and weathering are thus two interrelated processes affecting mainly the superficial layers of the mountains which are the sites of large rockslides (Furuya et al., 1999; Brueckl and Parotidis, 2001; Bonzanigo et al., 2001; Fabbri and Cappa, 2001).

Rock strength reduction is thus a time dependent process, characterised by a heterogeneous spatial distribution which provides a possible explanation for the absence of clear correlation between rock mass strength and depth (Chigira, 2001). To a first approximation, the mountain structure can be considered as consisting of two parts: the core, a relatively strong part characterised by low alteration; and the shallow layer, much more densely fractured and therefore subjected to more important water circulation, hence weathering. The thickness of this altered part is generally of about $500-600 \mathrm{~m}$ as observed for example in the crystalline Alps (Maréchal, 1998).

In this paper we investigate the impact of slope-scale shallow heterogeneities (weak zones and fractures) on the large scale translational rockslides (Varnes, 1978; Cruden and Varnes, 1996) initiation and geometry through a physical modelling technique. The latter is based on the use of 


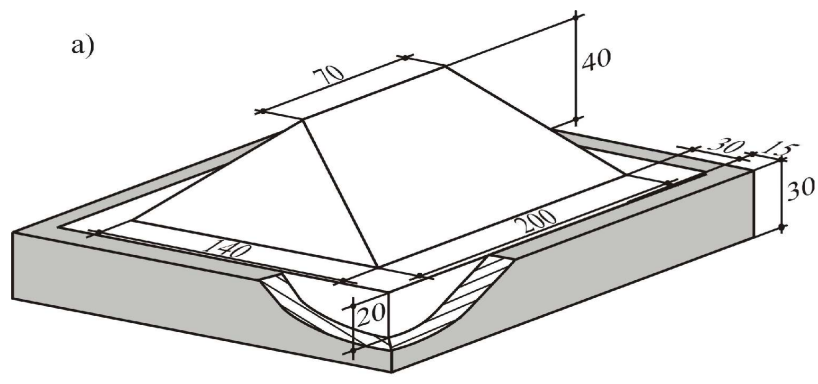

b)

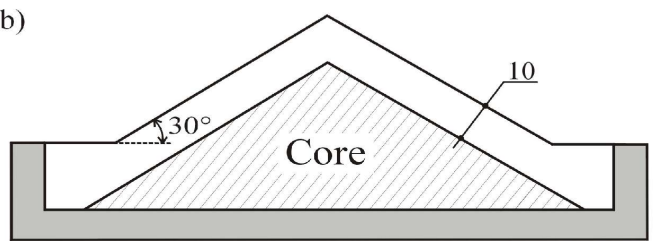

Fig. 1. Sketch of the model (dimensions are in millimetres). (a) The model is composed of a prismatic mountain with all four faces dipping at an angle of $30^{\circ}$ and a parallelepiped basement within a rigid box. (b) Cross section.

specially created "scaled" analogue materials as well as a vertical accelerator device (Chemenda et al., 2004 ${ }^{1}$ ). This modelling technique also allows the analysis of the threshold strength of the natural shallow slope levels (recalculated following similarity criteria) for which gravitational failure occurs.

\section{Experimental set up and procedure}

During an experiment, the model (Fig. 1) is put onto the mobile platform of the vertical accelerator device (Fig. 2). The accelerator works as follows: the mountain model is lifted up to $2 \mathrm{~m}$ and then dropped. During free fall the model reaches a maximal velocity of $6 \mathrm{~m} / \mathrm{s}$ just before coming into contact with an Enidine ${ }^{\circledR}$ shock absorber. The model is then rapidly but smoothly decelerated to zero velocity on the $5 \mathrm{~cm}$ stroke of the shock absorber. During this phase, the model undergoes strong acceleration (up to a factor 50) $g^{m}$ acting in the same direction as the gravity force. The magnitude and the duration of the acceleration phase are measured with a high frequency accelerometer fixed to the platform (Fig. 3).

The model is subject to a sequence of acceleration stages during which its surface deformation is observed and registered by using high resolution digital camera. Normally, about 100 acceleration stages are needed to obtain a well visible macro fracture at the model surface. This accelerator device allows the increase of the "acceleration of gravity" up to factor 50, and to precisely analyse, step by step, the phases of landslide initiation and evolution.

\footnotetext{
${ }^{1}$ Chemenda, A., Bouissou, S., and Bachmann, D.: 3-D Physical modelling of Deep-Seated Landslides: new technique and first results, J; Geophys. Res., submitted, 2004.
}

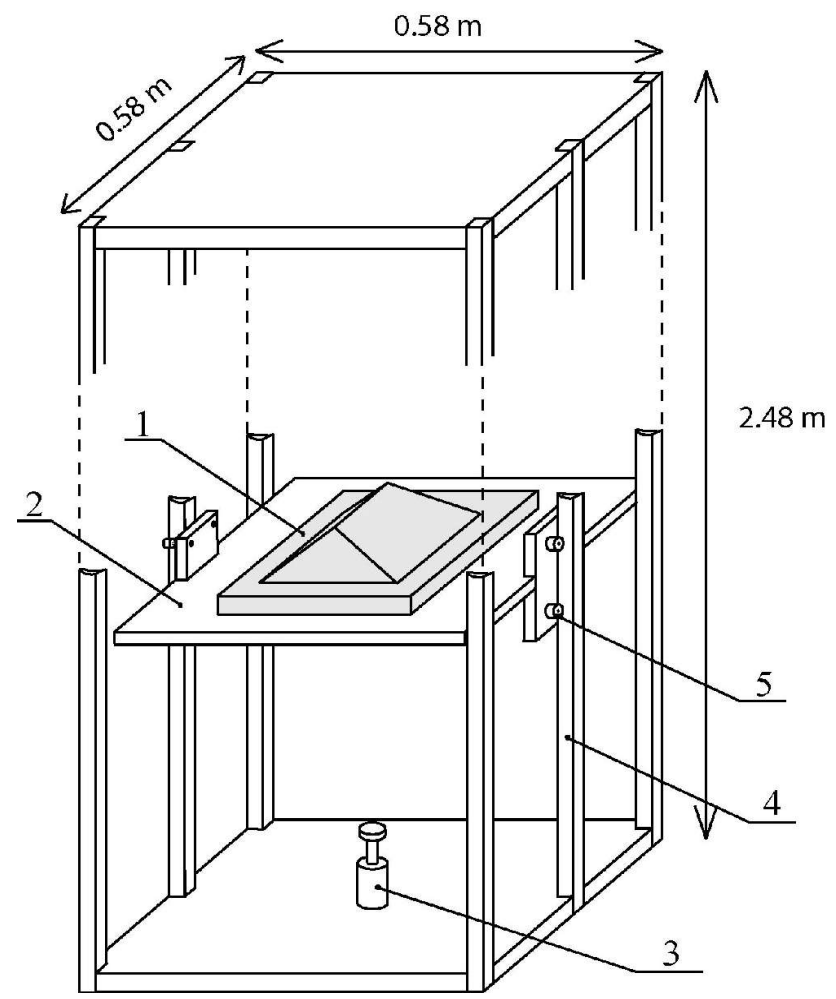

Fig. 2. Sketch of the vertical accelerator device designed to increase the "gravity force": 1) Model; 2) Mobile platform supporting the model, 3) Shock absorber, 4) Rails guiding the falling platform, and 5) Ball bearings.

In the simplest case, the model has a simple prismatic (ridge) shape with parallelepiped basement (Fig. 1a). The model is placed into a rigid box which prevents any displacement of the model basement. As indicated above, the model is composed of two parts made of different materials: a strong internal part and a weak (weathered) superficial part. High coupling is imposed between the two model parts by using a grooved interface. The strength of the interface is thus comparable to that of the weaker material. The upper part is made of the material "RockMass1" and is $1 \mathrm{~cm}$ thick. The internal part of the model is made of a stronger material "RockMass2". Both analogue materials represent compositional systems based on liquid and solid hydrocarbons with different additions. They possess elasto-brittle-plastic-viscous properties with a Von-Misès criterion. These properties depend on the material's composition, but also on the temperature and strain rate (Chemenda et al., 2004 ${ }^{1}$ ). Variation of these parameters allows us to obtain the required properties. Temperature allows to control both the material strength and its softening (Fig. 4). The higher the softening the more brittle the material is. The fracturing capacity (e.g. brittle behaviour) is thus controlled by temperature. Strain rate parameter allows to control the viscous behaviour. We have to find conditions under which viscosity can be neglected as rocks of the upper crust are not sensitive to the strain rate (Kohlstedt et al., 1995). This is obtained for the strain rate of 


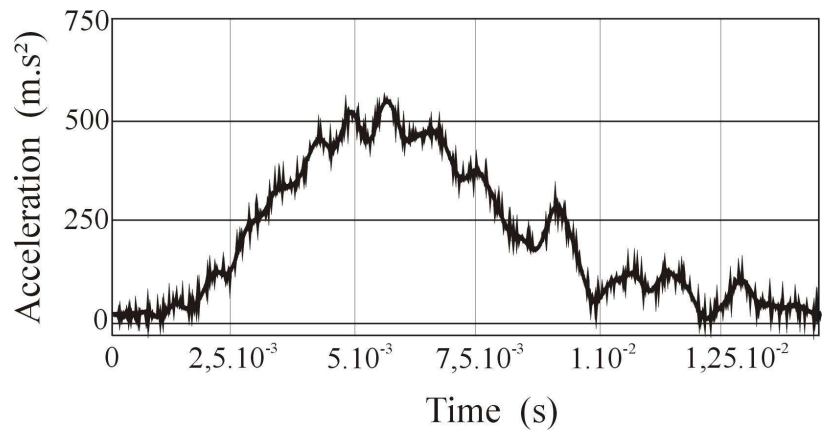

Fig. 3. Accelerogram recorded by the high frequency accelerometer fixed to the mobile platform of the accelerator shown in Fig. 2.

about $0.1 \mathrm{~s}^{-1}$ we imposed to our models (Chemenda et al., $2004^{1}$.)

To be scaled, the materials parameters have to satisfy the following similarity criteria:

$\frac{\sigma_{c}^{o}}{\rho^{o} g^{o} H^{o}}=\frac{\sigma_{c}^{m}}{\rho^{m} g^{m} H^{m}}$

$\frac{E^{o}}{\sigma_{c}^{o}}=\frac{E^{m}}{\sigma_{c}^{m}}$

$\frac{\sigma_{t}^{o}}{\sigma_{c}^{m}}=\frac{\sigma_{t}^{m}}{\sigma_{c}^{m}}$,

where $\rho g$ is the specific weight ( $\rho$ is the density, and $g$ is the gravity acceleration), $\sigma_{c}$ the strength under compression, $\sigma_{t}$ the strength under tension, $H$ the spatial scale of the phenomenon (the mountain height $H$, for example), $E$ the Young modulus, and superscripts " $o$ " and " $m$ " mean original (for the natural conditions) and model, respectively.

In the present study we fixed the size of the model $H^{m}$ and the strength $\sigma_{c}^{m}$ of the analogue materials, and vary the acceleration $g^{m}$ until rupture of the mountain model was reached. We performed series of about a hundred accelerations stages at a given vertical ("gravity") acceleration $g^{m}$. If no rupture occurred we then increased this vertical acceleration $g^{m}$ and performed another series of acceleration stages until rupture was obtained. The compressive strength of RockMass 1 is of $2600 \mathrm{~Pa}$ and that of RockMass 2 is about 10 times greater, although the exact value of this parameter is not important: it should be strong enough for the internal model part not to fail during the experiment. Both materials have almost the same Young modulus of about $5 \times 10^{5} \mathrm{~Pa}$. Considering the strength of the analogue material and the vertical acceleration $g^{m}$ under which experiments are conducted, according to Eq. (1), the scaling factor turns out to be $1 / 50000(1 \mathrm{~cm}$ in the model represents $500 \mathrm{~m}$ in nature).

Four model configurations were tested. In a first set of experiments, we considered a mountain with two homogeneous levels as shown in Fig. 2. In a second set of tests, we studied the impact of the pre-existing fractures perpendicular to the slope surface. Fractures spacing is $1.5 \mathrm{~cm}$, corresponding to
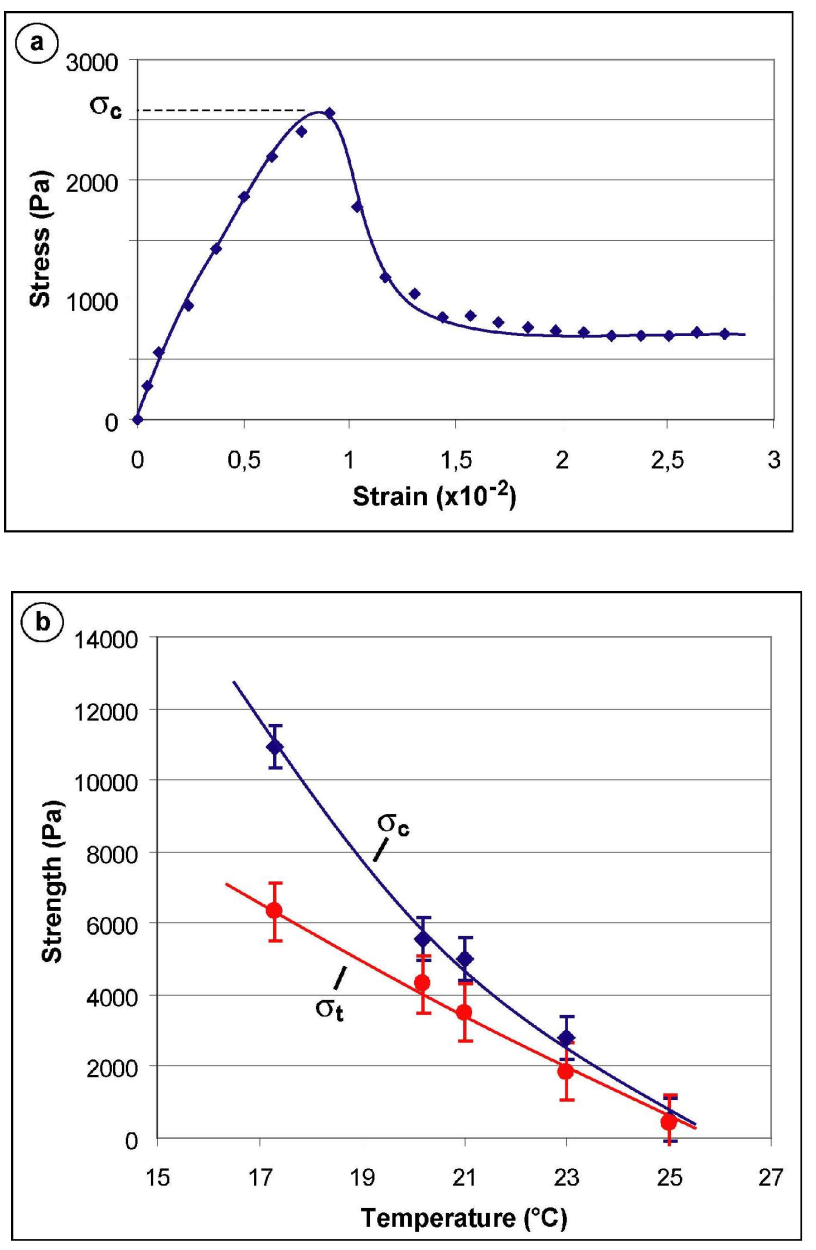

Fig. 4. Properties of the materials (a) Sress/Strain diagram: uniaxial compression test of RockMass 1 at strain rate $\dot{\varepsilon}=0.1 \mathrm{~s}^{-1}$ and temperature $\mathrm{T}=23^{\circ} \mathrm{C}$; (b) Compressive $\sigma_{c}$ and tensile $\sigma_{t}$ strength versus temperature.

$750 \mathrm{~m}$ in nature. They cut the whole shallow layer, and intersect the surface with various orientations (parallel, perpendicular or oblique to the slope). In a third set of trials, in the shallow low strength material, planar circular zones of weakness $(4 \mathrm{~cm}$ in diameter, representing $2 \mathrm{~km}$ in nature) parallel to the slope surface and located at $7 \mathrm{~mm}$-depth $(350 \mathrm{~m}$ in nature), were introduced, simulating highly weathered zones. Finally, in the fourth set of experiments we combined localized zones of weakness parallel to the slope surface with preexisting large scale fractures.

\section{Results}

A total of about 50 experiments were performed. Below, the results obtained in the four most representative experiments are described (Figs. 5, 6, 7 and 8). For all experiments failure occurred after about a hundred acceleration stages. 


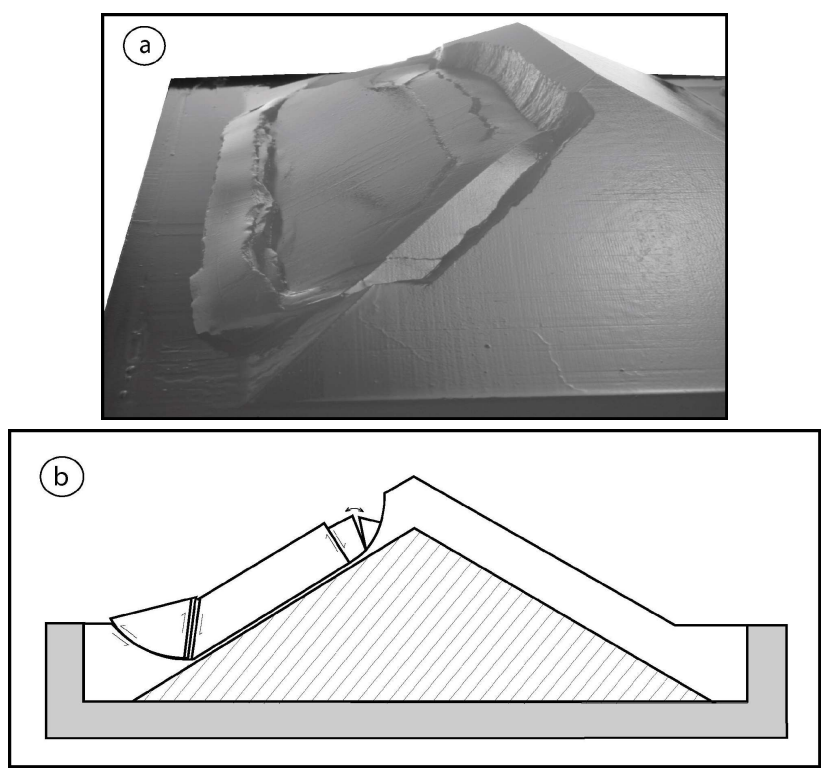

Fig. 5. Experiment 1. Model with both homogeneous parts, $g^{m}=500 \mathrm{~m} / \mathrm{s}^{2}$. (a) Picture of the experimental result, (b) Vertical cross section of the model.

\subsection{Experiment 1: Model with homogeneous shallow weak part}

The first evidence of fracturing occurs in this model at "gravity" acceleration $g^{m}=500 \mathrm{~m} / \mathrm{s}^{2}$ (Fig. 5). According to Eq. (1), the equivalent upper layer strength in nature is $\sigma_{c}^{o}=20 \mathrm{MPa}$. As expected, rupture occurs within the low strength model part and almost at its base (Fig. 5b). The upper limit of the failure zone is located close to the crest. Laterally, the limits of the sliding mass are located on the adjacent faces near the lateral crests. At the upper part of the sliding unit, one can observe extension cracks that evolve as normal faults. Normal faults were also observed on back scarps at the upper third of the mobilized mass. At the toe of the moving mass the thrust faulting is dominating and generates an elevated wedge (Fig. 5).

\subsection{Experiment 2: Model with a fractured weak superficial part}

The minimal gravity acceleration at which rupture of this model is initiated is again $g^{m}=500 \mathrm{~m} / \mathrm{s}^{2}$ (Fig. 6). Equivalent strength for natural rocks is thus $\sigma_{c}^{o}=20 \mathrm{MPa}$. Whatever fractures orientation, the rupture always occurs within (at the base of) the low strength upper layer and involves nearly a whole face of the model. Pre-existing fractures control the shape of the sliding unit, depending on their orientation. Vertical fractures limit the unit laterally (Fig. 6a). Only some of these fractures exhibit shear displacement. A differential motion is thus sometimes observed in association with various sizes of elevated wedges at the toe of the slope. In case of horizontal fractures, one of them delimits the upper part of the unit (Fig. 6b), and no extension cracks in its upper part
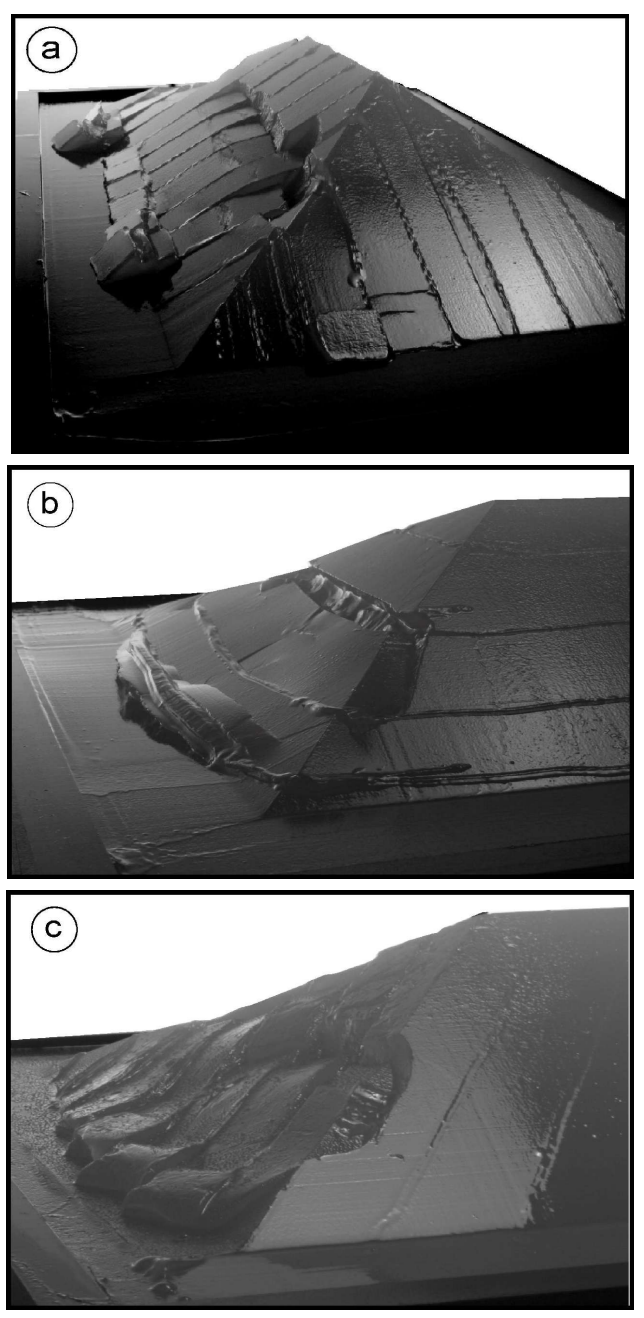

Fig. 6. Experiment 2. Three models with pre-existing large scale fractures with a spacing of $1.5 \mathrm{~cm}$ which corresponds in nature to $750 \mathrm{~m}$. The experiment was conducted under vertical acceleration $g^{m}=500 \mathrm{~m} / \mathrm{s}^{2}$. Fractures are perpendicular to the slope surface and intersect slope surface with different orientations. (a) Along slopedip fractures, (b) Horizontal fractures, (c) Oblique fractures.

were recognised as previously (Fig. 5a). Oblique fractures have more complicated effect, limiting the unit laterally but also guiding the direction of sliding (Fig. 6c).

3.3 Experiment 3: Model with local circular (4 cm in diameter) weak zone parallel to the slope surface, located at a $7 \mathrm{~mm}$-depth (350 $\mathrm{m}$ in nature)

In this trial the fracturing occurs at a minimal "gravity" acceleration $g^{m}=250 \mathrm{~m} / \mathrm{s}^{2}$ (Fig. 7). Equivalent strength in nature is thus $\sigma_{c}^{o}=10 \mathrm{MPa}$, thus half the strength found in the previous experiments. As previously, the rupture occurs in the low strength upper layer. It is initiated on the local weak zone, so the thickness of the sliding unit is defined by the depth of the local weak zone. The rupture propagates parallel to the slope surface and then reaches the surface along curved trajectories on the upper part of the future sliding mass (Fig. 7a). This 

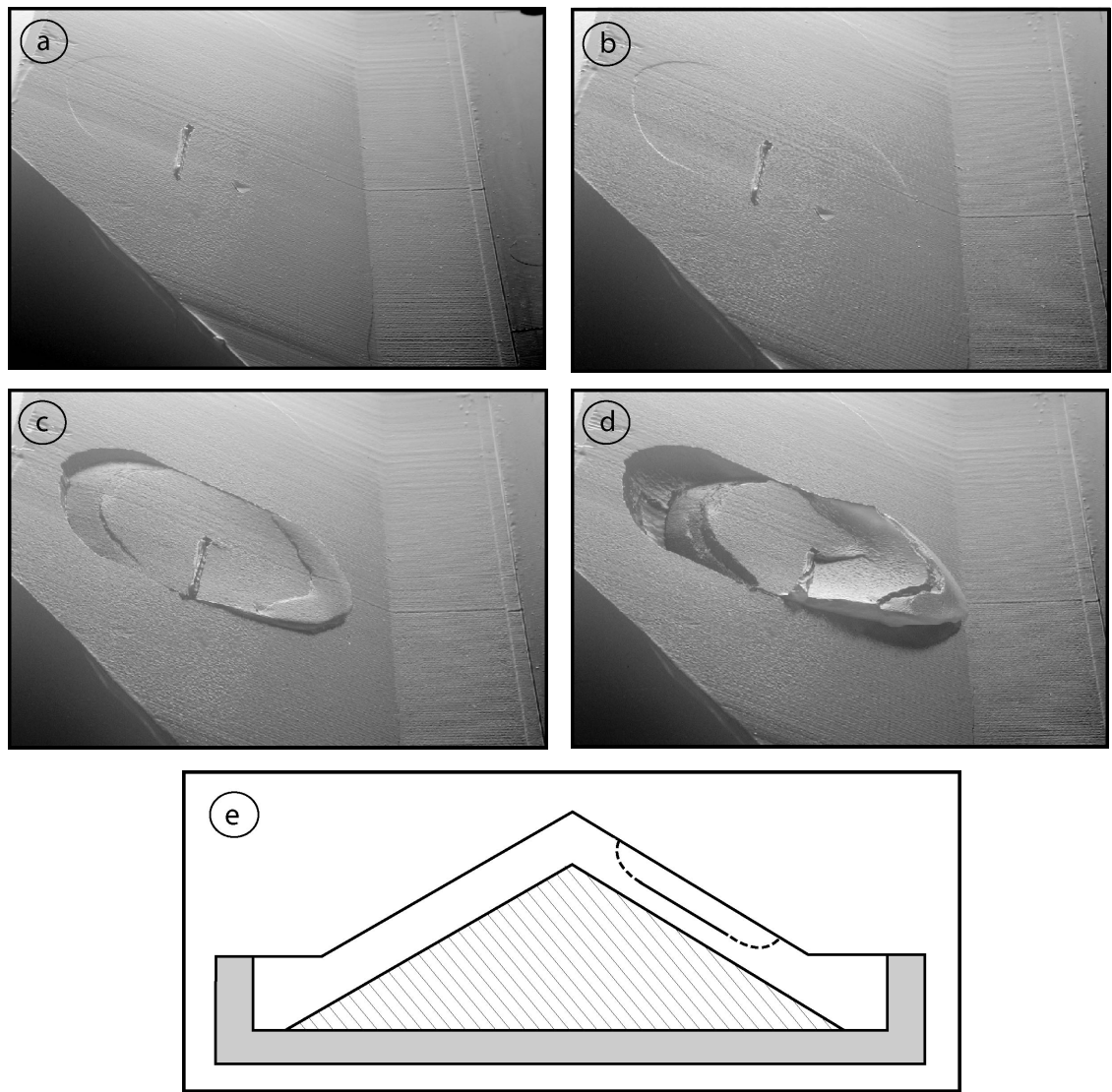

Fig. 7. Experiment 3. Model with a circular weak zone $(4 \mathrm{~cm}$ in diameter $)$ parallel to the slope surface located at $7 \mathrm{~mm} \mathrm{deep.} \mathrm{g}^{\mathrm{m}}=250 \mathrm{~m} / \mathrm{s}^{2}$ (a) After 97 acceleration stages, (b) After 99 acceleration stages, (c) After 108 acceleration stages, (d) After 119 acceleration stages (e) Vertical cross section of the model: dark line in the superficial layer represents the pre-existing weak zone, dashed lines represent the gravity-induced fractures.

rupture propagates then downward (Fig. 7b). The unit undergoes then large deformation with formation of tension cracks developing as normal faults in its upper part, and thrust faults at its toe (Fig. 7c). During the motion of the sliding unit, these thrust faults react as normal faults when passing the initial lower limit of the sliding mass (Fig. 7d).

3.4 Experiment 4: Model containing both pre-existing fractures orthogonal to the slope surface and weak circular zone parallel to the slope surface

As in the previous trial, rupture is initiated at $g^{m}=250 \mathrm{~m} / \mathrm{s}^{2}$ for an equivalent strength in nature $\sigma_{c}^{o}=10 \mathrm{MPa}$ (Fig. 8). In both cases the sliding unit is of limited extent. The size of the landslide in the slope-parallel directions is comparable to that of the weak (weathered) zone, but the influence of preexisting fractures on the sliding unit geometry is also evident and comparable to that of the experiment 2 (as can be seen in Fig. 6). In case of horizontal fractures, one of the fractures delimits the upper part of the sliding mass (Fig. 8a). For vertical fractures, the sliding unit is limited laterally by two fractures (Fig. 8b). Oblique fractures limit the unit laterally and guide the sliding direction (Fig. 8c).

\section{Discussion and conclusion}

The models considered in this study consist of two parts, an upper weak one and a lower strong one. This is the general case of crystaline massifs (Maréchal, 1998). Field observations of large-scale landslides in those massifs seem to indicate that the internal (core) part of the mountain is generally too strong to be affected by the gravity-induced rupture (Parise et al., 1997). The suggested reasons for that are: (a) relatively high lithostatic pressure and hence frictional strength; (b) less dense fracturing (than within the superficial layers) and smaller water circulation which delays the weathering process (strength reduction). In the present study, our models are thus suitable for the analysis of rockslides initiation and evolution in crystalline rocks, where many landslides occur (Furuya et al., 1999; Chigira, 2001).

Performed experiments showed that gravity instability always occurs in the weak part. When heterogeneities were present, the greatest effect was observed for localised weak zones sub-parallel to the slope surface. In real natural cases, such weak zones may correspond to highly fractured/weathered zones. Landslides can easily be initiated at this zone and therefore this should be the most common land- 
sliding type, whatever the deeper structure is. If weathering occurs more homogeneously in the upper layer, more time (greater strength reduction of this layer) is needed to reach instability conditions, and landsliding occurs in this case at the whole slope scale.

One could imagine that all kinds of local weakness zones should facilitate rockslides triggering. Contrary to these expectations, large scale fractures don't enable landslide initiation for a higher shallow level strength. These heterogeneities however affect the shape of the sliding units. This was the case in all reported experiments which have one common feature: the internal part of the mountain is too strong to be affected by failure. We adopted such a structure on purpose to separate effects (scales), but is this realistic? Probably not, at least in some cases where deformation occurs at the whole mountain scale, in a deep-seated gravitational slope deformation way (Iovine and Tansi, 1998; Crosta and Zanchi, 2000; Agliardi et al., 2001), with sometimes obvious gravity-driven reactivation of the tectonic faults (Rizzo and Leggeri, 2004, Di Luzio et al., 2004). This phenomenon however refers to another geological scale. In this case, strength reduction affects the whole mountain, and not only the shallower layer.

Acknowledgements. Authors are grateful to G. B. Crosta and an anonymous referee for their helpful comments and suggestions which improved the manuscript.

Edited by: M. Jaboyedoff

Reviewed by: G. B. Crosta and another referee

\section{References}

Agliardi, F., Crosta, G., and Zanchi, A.: Structural constraints on deep-seated slope deformations kinematics, Eng. Geol., 59, 83102, 2001.

Augustinus, P. C.: Glacial valley cross-profile development: the influence of in situ rock stress and rock mass strength, with examples from the Southern Alps, New Zealand, Geomorphology, 14, 87-97, 1995.

Bonzanigo, L., Eberhardt, E., and Loew, S.: Hydromechanical factors controlling the creeping Campo Vallemaggia landslide, Proceeding: Landslides-Causes, impacts and countermeasures, Davos, Switzerland, 13-22, 2001.

Brueckl, E. and Parotidis, M.: Estimation of large-scale mechanical properties of a large landslide on the basis of seismic results, Int. J. Rock Mech. Min. Sci. 38, 877-883, 2001.

Chigira, M.: Mass rock creep of crystalline schist: minor structures formed by mass rock creep, J. Jap. Soc. Eng. Geol. 26, 25-79, 1985.

Chigira, M.: Micro-sheeting of granite and its relationship with landsliding specially after the heavy rainstorm in June 1999, Hiroshima prefecture, Japan, Eng. Geol., 29, 219-231, 2001.

Crosta, G. and Zanchi, A.: Deep seated slope deformations. Huge, extraordinary, enigmatic phenomena, in: Proceeding of the 8th International Symposium on Landslides, edited by Bromhead, E., Cardiff, 126-131, 2000.

Cruden, D. M. and Varnes, D. J.: Landslide types and processes, in: Landslides Investigation and Mitigation, edited by Turner, A. K.,
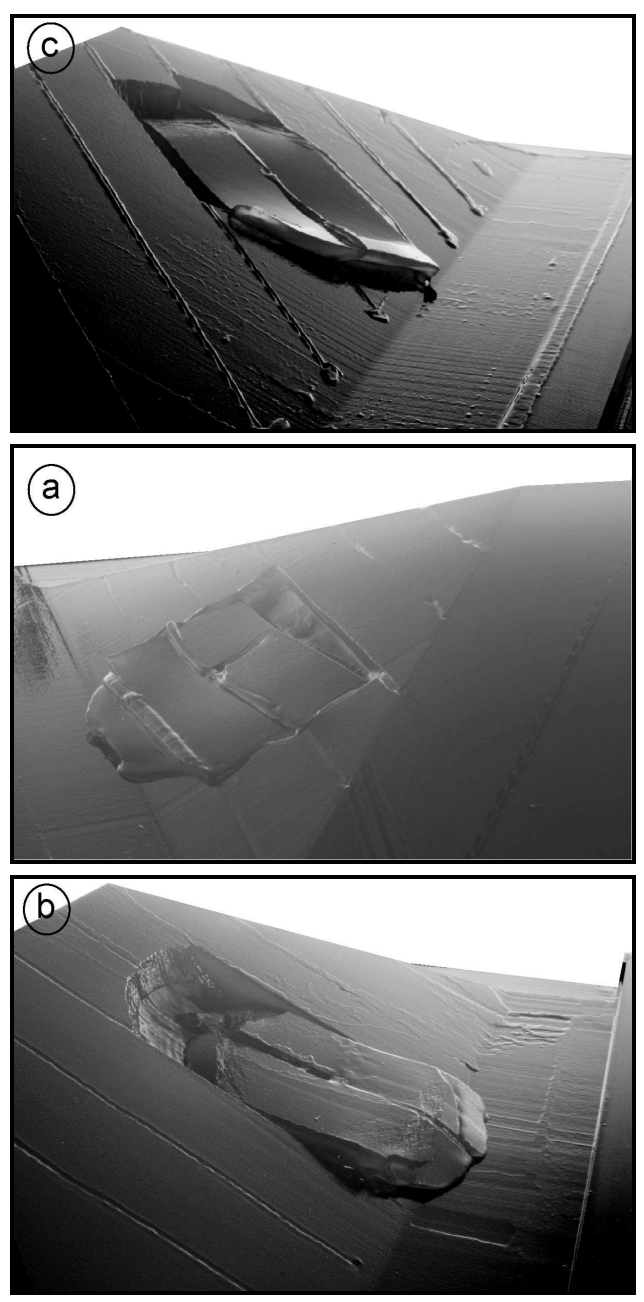

Fig. 8. Experiment 4. Model containing both a local weak zone sub-parallel to the slope surface and differently oriented fractures perpendicular to the slope, $g^{m}=250 \mathrm{~m} / \mathrm{s}^{2}$. (a) Fractures with horizontal surface traces, (b) Vertical fractures, (c) Oblique fractures.

and Schuster, R. L., National Research Council, Transportation Research Board, Special Report 247, 36-75, 1996.

Di Luzio, E., Saroli, M., Esposito, C., Bianchi-Fasani, G., Cavinato, G. P., and Scarascia-Mugnozza, G.: Influence of structural framework on mountain slope deformation in the Maiella anticline (Central Apennines, Italy), Geomorphology, 60, 417-432, 2004.

Fabbri, O. and Cappa, F.: Apports de l'analyse structurale à la compréhension de la dégradation du glissement de la Clapière, Massif du Mercantour, Alpes Maritimes. S. Spé. Soc. Géol. Fr., 13-14, 2001.

Furuya, G., Sassa, K., Hiura, H., and Fukuoka, H.: Mechanism of creep movement caused by landslide activity and underground erosion in crystalline schist, Shikoku Island, southwestern Japan, Eng. Geol., 53, 311-325, 1999.

Gillon, M. D. and Hancox, G. T.: Cromwell Gorge landslides : a general overview, in: Proceedings 6th Int. Symp. Landslides, edited by Bell, D., Christchurch, Balkema, Rotterdam, 83-102, 1992. 
Iovine, G. and Tansi, C.: Gravity accomodated 'structural wedges' along thrust ramps: a kinematic scheme of gravitational evolution, Natural Hazards, 17, 195-224, 1998.

Kohlstedt, D. L., Evans, B., and Mackwell, S. J.: Strength of the lithosphere; constraints imposed by laboratory experiments, J. Geophys. Res., 100, 17 587-17 602, 1995.

Maréchal., J. C.: Les circulations d'eau dans les massifs cristallins alpins et leurs relations avec les ouvrages souterrains, Thesis 1769, EPF, Lausanne, 298, 1998.

Maréchal., J. C., Wyns, R., Lachassagne, P., Subrahmanyan, K., and Touchard, F.: Anisotropie verticale de la perméabilité de l'horizon fissuré des aquifères de socle: concordance avec la structure géologique des profils d'altération, C. R. Geoscience, $335,451-460,2003$.
Parise, M., Sorriso-Valvo, M., and Tansi, C.: Mass movements related to tectonics in the Aspromonte massif (southern Italy), Eng. Geol., 47, 89-106, 1997.

Rizzo, V. and Leggeri, M.: Slope instability and sagging reactivation at Maratea (Potenza, Basilicata, Italy), Eng. Geol., 71, 181198, 2004.

Varnes, D. J.: Slopes movements types and processes, In: Landslides: analysis and control, edited by Schuster, R. L. and Krizek, R. J., Transportation Research Board, National Academy of Science, special report 176, 2, 11-33, 1978.

Wyns, R., Gourry., J. C., Baltassat;, J. M., and Lebert, F.: Caractérisation multiparamètres des horizons de subsurface $(0$ $100 \mathrm{~m}$ ) en contexte de socle altéré, in $2^{\mathrm{e}}$ colloque GEOFCAN, BRGM, IRD, UPMC, 105-110, 1999. 